Subjetividade na cidade: uma análise da modernidade na obra poética de Mário Quintana

\title{
Subjetividade na cidade: uma análise da modernidade na obra poética de Mário Quintana
}

Priscila Viana Alves - Mestranda pelo Programa de Pós-Graduação em Geografia pela Universidade Federal Fluminense - Campos dos Goytacazes. Bolsista da FAPERJ. Integra o Laboratório de Pesquisa Cultura, Planejamento e Representações Espaciais (LabCult). E-mail: prittyviana@hotmail.com

Elis de Araújo Miranda - Professora da Universidade Federal Fluminense, Departamento de Geografia de Campos. Doutora em Planejamento Urbano e Regional pelo IPPUR/ UFRJ. Mestre em Planejamento do Desenvolvimento, pelo NAEA/UFPA. Coordena o Laboratório: Cultura, Planejamento e Representação Espacial - CULT/UFF. E-mail: elismiranda10@gmail.com

\section{Resumo}

$\mathrm{O}$ artigo discute a cidade no advento da modernidade e o fenômeno da rua como espaço privilegiado de constituição do lugar. $\mathrm{Na}$ cidade moderna a experiência foi abolida pela lógica mercadológica do capitalismo, deste modo não há tempo para vivenciar o espaço urbano e fazer deste um lugar. Assim, a arte, sobremodo a literatura, consiste em um poderoso meio para a experimentação do espaço, o que será evidenciado na obra poética de Mário Quintana.

\begin{abstract}
The article discusses the city in the advent of modernity and the street phenomenon as a privileged space of place constitution. Experience was abolished in the modern city by capitalism market logic, so there is no time to experience the urban space and make of it a place. Thus art, most of all literature, consists of a powerful means for space experimentation, which will be evidenced in the poetic work of Mario Quintana.
\end{abstract}

\section{Palavras-chave}

Cidade. Modernidade. Literatura. Lugar. Mário Quintana.

\section{Keywords}

City. Modernity. Poetry. Mario Quintana. 


\section{INTRODUÇÃO}

O objetivo deste artigo é analisar a cidade na modernidade por meio de autores como Henri Lefebvre e Walter Benjamin. Essa interseção elucidará uma possível leitura sobre as transformações no espaço urbano na cidade de Porto Alegre, no Sul do Brasil, a partir da leitura das poesias de Mário Quintana, orientado pela obra de Benjamin sobre Baudelaire. Os poetas compreendem e sentem as transformações no espaço urbano claramente e eternizam-nas em sua obra. Compreende-se que a leitura simbólica do espaço não se opõe à leitura realizada pela ciência, pelo contrário, estas diferentes leituras podem solidariamente ampliar o conhecimento de mundo dos sujeitos.

Mário de Miranda Quintana, poeta gaúcho, nasceu na cidade de Alegrete, em 30 de junho de 1906, e faleceu em 1994, em Porto Alegre. A capital gaúcha foi sua morada em grande parte de sua vida e suas experiências nesta cidade, como expressam seus poemas. Pode-se afirmar que a obra de Mário Quintana retrata um encontro da Literatura e da Geografia, a literatura e com a sua linguagem poética, e a Geografia, e com a descrição da Geograficidade (DARDEL, 2015) nas experiências poéticas em Porto Alegre, o seu lugar (TUAN, 2013).

\section{A CIDADE NA MODERNIDADE}

O sistema capitalista engendra o espaço segundo os interesses de mercado e não tem compromisso em manter os laços afetivos dos sujeitos com o lugar. Como afirma Henri Lefebvre (1999, p. 27), “o espaço e a política do espaço 'exprimem' as relações sociais, mas reagem sobre elas". Ou seja, o espaço se transforma conforme a sociedade em cada período histórico.

Diante da crise da sociedade urbana, Lefebvre dialoga com argumentos a favor e contra a rua e a cidade. Para ele a rua é o lugar privilegiado da experiência e da interação social. A favor da rua ele elenca alguns argumentos tais como: a rua como lugar de encontro, a rua tem função informativa, tem função simbólica e lúdica, os acontecimentos revolucionários acontecem na rua. É no espaço de todos que se exprimem as necessidades pessoais.“A rua? É o lugar (topia) do encontro, sem o qual não existem outros encontros possíveis nos lugares determinados (cafés, teatros, salas diversas). Esses lugares privilegiados animam a rua e são favorecidos por sua animação, ou então não existem"(LEFEBVRE, 1999, p. 29).

$\mathrm{Na}$ cidade moderna a experiência foi abolida pela lógica mercadológica do capitalismo, deste modo não há tempo para vivenciar o espaço urbano e fazer deste um lugar. Destarte, têm-se argumentos contra a rua: encontros superficiais, 
a lógica do lucro desenvolve-se na rua, lugar privilegiado da repressão, passagem solitária. Lefebvre fala de uma "colonização do espaço urbano" (1999, p. 31) por meio da publicidade. Isto é a apropriação privada do espaço coletivo.

A cidade inteira é apropriada pelo mundo da mercadoria, pois o valor de troca se sobrepôs ao valor de uso do espaço da rua. Os mercadores tornaram-se os mestres e não mais os sujeitos se apropriam coletivamente do espaço, posto que este se tornou palco privilegiado de compra e venda de objetos. Lefebvre afirma que

O mundo da mercadoria desenvolve-se na rua. A mercadoria que não pode confinar-se nos lugares especializados, os mercados (praças...) invadiu a cidade inteira. $\mathrm{Na}$ antiguidade as ruas eram apenas anexos dos lugares privilegiados: o templo, o estádio, a ágora, o jardim. Mais tarde, na Idade Média, o artesanato ocupava as ruas. $\mathrm{O}$ artesão era, ao mesmo tempo, produtor e vendedor. Em seguida, os mercadores, que eram exclusivamente mercadores, tornaram-se os mestres. A rua? Uma vitrina, um desfile entre as lojas. A mercadoria, tornada espetáculo umas para as outras. Nela, mais que noutros lugares, a troca e o valor de troca prevalecem sobre tudo, até reduzi-lo a um resíduo (1999, p. 30-31).

Marshall Berman (1986), ao falar dos paradigmas do planejamento urbano do século XX, idealizado por Le Corbusier e seu "homem novo" da modernidade, afirma que será o "homem do carro". A rua, deste modo, não é mais do encontro dos sujeitos, mas sim dos passantes e consumidores que não mantém relações perenes com o lugar.

\section{Segundo Berman,}

Nessa rua, como na fábrica moderna, o modelo mais bem equipado é o mais altamente automatizado: nada de pessoas, exceto as que operam as máquinas; nada de pedestres desprotegidos e desmotorizados para retardar o fluxo. "Cafés e pontos de recreação deixarão de ser os fungos que sugam a pavimentação de Paris”. Na cidade do futuro, o macadame pertencerá somente ao tráfego (1986, p. 161).

Berman debate o ser humano na cidade moderna, lançado ao caos e que necessita sobreviver se adaptando a ele. É preciso moldar o corpo, mas também a sensibilidade para alcançar novos procedimentos para sobreviver, pois o novo tempo requer especificidades. O autor dá o exemplo de Baudelaire:

O homem na rua moderna, lançado nesse turbilhão, se vê remetido aos seus próprios recursos - frequentemente recursos que ignorava possuir - e forçado a explorá-los de maneira desesperada, a fim de sobreviver. Para atravessar o caos, ele precisa estar em sintonia, precisa adaptar-se aos movimentos do caos, precisa aprender não apenas a por-se a salvo dele, 
mas a estar sempre um passo adiante. Precisa desenvolver sua habilidade em matéria de sobressaltos e movimentos bruscos, em viradas e guinadas súbitas, abruptas e irregulares - e não apenas com as pernas e o corpo, mas também com a mente e a sensibilidade. Baudelaire mostra como a vida na cidade moderna força cada um a realizar esses novos movimentos; mas mostra também como, assim procedendo, a cidade moderna desencadeia novas formas de liberdade. Um homem que saiba mover-se dentro, ao redor e através do tráfego (BERMAN, 1986, p. 154).

Lefebvre, ao falar de Le Corbusier, diz que este suprimiu a rua com a criação dos "novos conjuntos" e viu as consequências "a extinção da vida, a redução da "cidade" a dormitório, a aberrante funcionalização da existência. A rua contém as funções negligenciadas por Le Corbusier: a função informativa, a função simbólica, a função lúdica. Nela joga-se, nela aprende-se" (LEFEBVRE, 1999, p. 30).

A defesa da rua feita por Henri Lefebvre evidencia a importância da cidade concebida como reunião, simultaneidade e do encontro entre os sujeitos que habitam o espaço urbano. Para a transformação da cidade da mercadoria, é necessária uma mudança na prática social, em que o espaço "lúdico", "vivido" superem os espaços de troca e circulação. "A passividade dos que habitam, mas que poderiam e deveriam 'habitar como poetas (Holderlin)" (LEFEBVRE, 1999, p. 165) é o apelo que Lefebvre faz para todos os habitantes da cidade.

Kuster e Pechman falam da rua das multidões, que seria a rua do século XIX, que foi destruída pelo avanço do capitalismo e pelas reformas urbanas. Estes "matam" a rua enquanto palco da experiência, o que resulta na perda da urbanidade, ou melhor, da identidade urbana. Para esses autores

As ruas tomadas pela multidão do século 19 não têm espaço no perfil que o modernismo planeja para a nova cidade, cuja prioridade é a circulação dos automóveis. Dentro dos objetivos traçados por esse novo ordenamento, a setorização que dividia o espaço urbano entre residências, trabalho, lazer e circulação visava eliminar a mistura de atividades que o caracterizava até então, eliminando também a grande quantidade de pessoas que transitavam a pé nas ruas (KUSTER; PECHMAN, 2014, p. 71-72).

Os habitantes da cidade são a partir do século XX reduzidos ameros consumidores e transeuntes, não são mais sujeitos que vivenciam e se apropriam politicamente da rua. A cidade capitalista construída e remanejada, segundo a lógica de circulação de lucro, destrói a possibilidade de apropriação coletiva, o que desencadeia na repartição do espaço urbano. No entanto, a arte pode ser um poderoso caminho de resgatar o brilho da cidade e da rua, pois ela pode ser apropriada por sujeitos que podem revelar seus encantos. 


\section{EXPERIÊNCIAS NA CIDADE}

Segundo Tuan (2013, p. 18), “[...] Experiência é aprender, significa atuar sobre o dado e criar a partir dele. $\mathrm{O}$ dado não pode ser conhecido em sua essência. O que pode ser conhecido é uma realidade que é um constructo da experiência, uma criação de sentimento e pensamento". Destarte, o espaço pode ser experienciado de diferentes maneiras, o que dependerá da forma que uma pessoa conhece e constrói a realidade por meio dos sentidos (visão, audição, olfato, paladar e tato) e da forma com que se percebe, vivencia, sente e experimenta o mundo.

Habitar na cidade é uma arte "[...] deixando a representação, o ornamento, a decoração, a arte pode se tornar práxis e poiesis em escala mundial: a arte de viver na cidade como obra de arte" (LEFEBVRE, 2006, p. 134). Isto quer dizer que o viver na cidade deve ser prazeroso e não perpassado por todo tipo de mazelas sociais. Todavia, a história do espaço no terceiro mundo é seletiva, isto é, o espaço é marcado pelas desigualdades de renda da sociedade.

As transformações mais enérgicas do espaço urbano na vida moderna podem ser percebidas pela arte, sobretudo pela literatura. "A manifestação das divisões de classe na cidade moderna implica divisões interiores no indivíduo moderno" (BERMAN, 1986, p. 148). A humanidade muda na medida em que a condições materiais se alteram. Walter Benjamin afirma, ao se referir a Baudelaire no início de sua trajetória poética, que ele desejava a conquista da rua:

Mais tarde, após abandonar, passo a passo, sua existência burguesa, a rua tornou-se para ele cada vez mais um refúgio. Mas na flanerie desde o início havia uma consciência da fragilidade desta existência. Na flanerie, a necessidade se faz uma virtude; o que mostra a estrutura característica da concepção do herói em Baudelaire em todas as suas manifestações (BENJAMIN, 1975, p. 7).

Benjamin, em um trecho de Rua de mão única, nomeado Sombras curtas, crítica a arquitetura do século XX, que diferente da arquitetura do século XIX, apaga os vestígios dos sujeitos:

Pois os novos arquitetos obtiveram isso com o seu aço e vidro: criaram espaços onde não é fácil deixar vestígios. "Depois do que foi dito" escreveu Scheerbarte já há vinte anos - "pode-se muito bem falar de uma 'cultura de vidro'. O novo ambiente de vidro transformará completamente o seu humano. E agora só resta desejar que a nova cultura de vidro não encontre oponentes em demasia" (1987, p. 266). 
Esse "ambiente de vidro" da modernidade condiciona a vivência dos indivíduos, pois modela segundo seus padrões as ações humanas. Deste modo, as relações sociais tornam-se ainda mais desgastadas, instáveis, em "choque". "A vida urbana moderna é caracterizada pela colisão de sensações fragmentadas e descontínuas" (EAGLETON, 2011, p. 114).

Para Walter Benjamin (1989), o lugar privilegiado do flâneur são as ruas pelos quais ele percorre e vivencia o espaço da cidade. Ele compara o flâneur ao poeta Baudelaire, pois este era observador atento das transformações de Paris do limiar da modernidade.

Para Benjamin:

A rua se torna moradia para o flaneur que, entre as fachadas dos prédios, sente-se em casa tanto quanto o burguês entre suas quatro paredes. Para ele, os letreiros esmaltados e brilhantes das firmas são um adorno de parede tão bom ou melhor que a pintura a óleo no salão do burguês; muros são a escrivaninha onde apoia o bloco de apontamentos; bancas de jornais são suas bibliotecas, e os terraços dos cafés, as sacadas de onde, após o trabalho, observa o ambiente. Que a vida em toda a sua diversidade, em toda a sua inesgotável riqueza de variações, só se desenvolva entre os paralelepípedos cinzentos e ante o cinzento pano de fundo do despotismo: eis o pensamento político secreto da escritura de que faziam parte as fisiologias (BENJAMIN, 1989, p. 35).

O flâneur é um detetive, justificativa para a sua "indolência" de observador de tudo a sua volta, o que pode ser comparado ao ofício do artista, do poeta. Os sujeitos experimentam o espaço da cidade por meio de uma percepção apurada.

Para tal a flanerie oferece as melhores perspectivas. "O observador - diz Baudelaire - é um príncipe que, por toda a parte, faz uso do seu incógnito". Desse modo, se o flâneur se torna sem querer detetive, socialmente a transformação lhe assenta muito bem, pois justifica a sua ociosidade. Sua indolência e apenas aparente. Nela se esconde a vigilância de um observador que não perde de vista o malfeitor. Assim, o detetive ve abrirem-se a sua autoestima vastos domínios. Desenvolve formas de reagir convenientes ao ritmo da cidade grande. Capta as coisas em pleno voo, podendo assim imaginar-se próximo ao artista (BENJAMIN, 1989, p. 38).

Benjamin, sobre Baudelaire diz que,

Fugindo dos credores, metia-se em cafés ou em círculos de leitura. Aconteceu de habitar dois domicílios ao mesmo tempo, mas, no dia em que o aluguel estava por vencer, pernoitava num terceiro, em casa de amigos. Vagueava, assim, pela cidade, que ha muito já não era a pátria do flaneur (BENJAMIN, 1989, p. 44-45). 
A arte tem a possibilidade de evidenciar as experiências humanas com o lugar, como colabora Tuan (2013, p. 200), é "uma função da arte literária é dar visibilidade a experiências íntimas, inclusive às de lugar". Sobretudo a literatura com alusão às pequenas coisas ao redor "que de outro modo passariam despercebidas"(TUAN, 2013, p. 200).

As expressões artísticas são meios pelos quais se apreende a realidade exterior. "A arte e a arquitetura buscam visibilidade. São tentativas de dar forma sensível aos estados de espírito, sentimentos e ritmos da vida diária. A maioria dos lugares não são criações deliberadas, eles são construídos para satisfazer necessidades práticas" (TUAN, 2013, p. 204).

Deste modo, os laços afetivos e práticos que ligam o ser humano à Terra e seus conhecimentos teórico e simbólico são fundamentais para a interpretação do mundo. A Geografia deve ser entendida como meio pelo qual a humanidade realiza a sua existência, o que significa afirmar que a Geografia é o caminho, a "base a partir da qual a consciência se desenvolve [...]" (DARDEL, 2015, p. 48). A consciência humana tem a sua fundação e seu limite na Terra, assim a realidade geográfica humana é o lugar onde se está, onde a presença humana se encontra.

O espaço urbano faz parte das experiências íntimas dos indivíduos, todavia, esta experiência tem se tornado mais supérflua. As percepções dos sujeitos em relação as suas habitações e ruas é que criam afetividade e o sentimento de lugar.

Para Tuan:

A rua onde se mora é parte da experiência íntima de cada um. A unidade maior, o bairro, é um conceito. O sentimento que se tem pela esquina da rua local não se expande automaticamente com o passar do tempo até atingir todo o bairro. $\mathrm{O}$ conceito depende da experiência, porém não é uma consequência inevitável da experiência (TUAN, 2013, p. 208).

As relações citadinas produzem significados que explicam que a "cidade é um lugar, um centro de significados, por excelência. Possui muitos símbolos bem visíveis. Mais ainda, a própria cidade é um símbolo" (TUAN, 2013, p. 211). As ruas são o palco em que os sujeitos dão visibilidade para as suas manifestações afetivas.

Tuan afirma que a cidade-estado da Grécia antiga "era suficientemente pequena para que todas as pessoas pudessem se conhecer pessoalmente" (TUAN, 2013, p. 215). Todavia “a moderna nação-estado é grande demais para ser assim experienciada. É preciso recorrer a meios simbólicos para que a grande nação-estado pareça um lugar concreto - não apenas uma ideia política - pelo qual o povo possa sentir uma profunda afeição" (TUAN, 2013, p. 215). Assim, a moderna cidade necessita essencialmente dos aspectos simbólicos para ser experienciada. 


\section{O POETA DA CIDADE}

Em sua poesia, Mario Quintana expressa sua experiência com a cidade de suas memórias e a cidade que se reconfigura na contemporaneidade. Em sua obra os lugares que não existem mais são exaltados, a cidade atual produz no poeta melancolia e desilusão. Mario Quintana morava em hotéis, lugares coletivos, e se inspirava nas ruas, lugares de passagens, todavia não perdia sua experiência pessoal, por isso mesmo era um flâneur. Para Benjamin: "havia o transeunte, que se enfia na multidão, mas havia também o flâneur, que precisa de espaço livre e não quer perder sua privacidade" (BENJAMIN, 1989, p. 50).

Merleau-Ponty corrobora,

Assim como a natureza penetra até no centro de minha vida pessoal, e entrelaça-se a ela, os comportamentos também descem na natureza e depositam-se nela sob a forma de um mundo cultural. Não tenho apenas um mundo físico, não vivo somente no ambiente da terra, do ar e da água, tenho em torno de mim estradas, plantações, povoados, ruas, igrejas, utensílios, uma sineta, uma colher, um cachimbo. Cada um desses objetos traz implicitamente a marca da ação humana à qual ele serve (MERLEAUPONTY, 2011, p. 465).

No universo de Quintana, quem merece sua atenção é justamente aquilo que no geral os indivíduos não dão valor e até mesmo nem pensam ser dignas de importância. O poeta tinha uma relação de intimidade e confiança com os objetos, os lugares e as coisas. Tudo se tornava poesia. Ele se apropriava do espaço da rua como espaço de vivência e não somente de passagem. Ou seja, valorizava como único e particular o de e para todos. "A Rua da Praia é o meu chão e o meu céu” (CARVALHAL, 1985).

Edgar Morin revela sobre a poesia,

A poesia, que faz parte da literatura e, ao mesmo tempo, é mais que a literatura, leva-nos à dimensão poética da existência humana. Revela que habitamos a Terra, não só prosaicamente - sujeitos à utilidade e à funcionalidade - mas também poeticamente, destinados ao deslumbramento, ao amor, ao êxtase. Pelo poder da linguagem, a poesia nos põe em comunicação com mistério, que está além do dizível (MORIN, 2003, p. 45).

A poesia revela em sua subjetividade o que o poeta apreende do mundo vivido e experiencia pelo desvelamento dos encantos da cidade. Ele revela sua sensibilidade ao reconhecer as cores que pode ter uma cidade. As alterações no aspecto do espaço revelam a mudança da própria sociedade. Mario Quintana evidencia seu raciocínio geográfico desenvolvido e sua representação do vivido 
examinado minuciosamente pela diferenciação dos espaços por detalhes singelos em sua estética e sua multiplicidade:

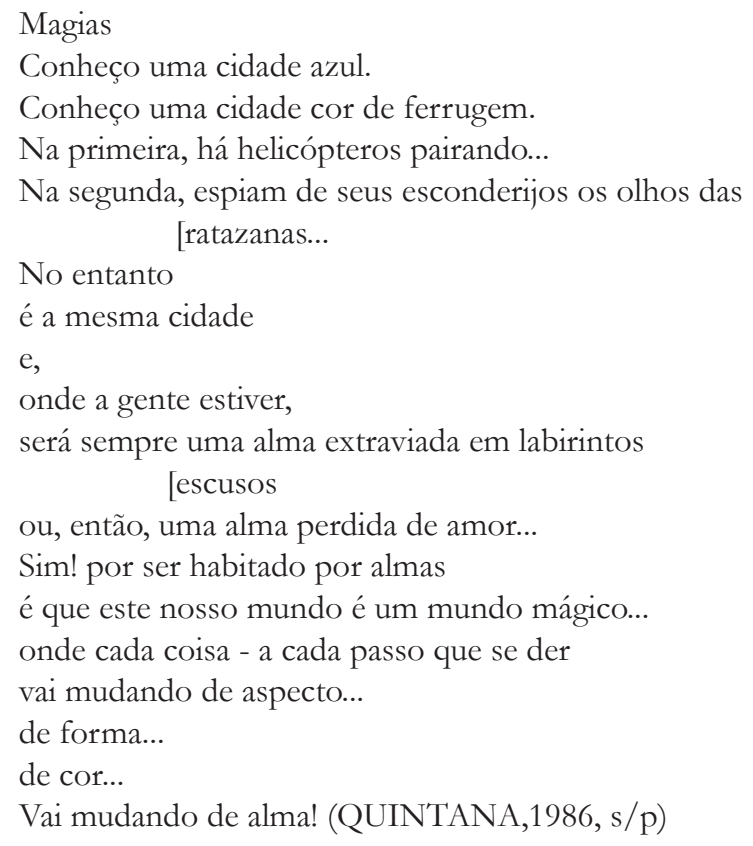

O autor fala das transformações urbanas de Porto Alegre e a praça agitada como centro da metrópole gaúcha. Pode-se comparar o desenvolvimento industrial e a urbanização "situando" e "ambientando" o cenário da cidade. Esta é palco da modernidade, local onde "homens passam", mas "nada veem". Esta é a principal característica do ser humano moderno que perdeu o sentido do flâneur. As mudanças provenientes da urbanização, isto é, o crescimento das cidades assustava o poeta e condenava ao desaparecimento muitos lugares outrora estimados. Acompanhou a evolução e a modificação espacial de Porto Alegre, mas preservou afetivamente em sua memória a sua paisagem pretérita:

\section{Urbanística}

Praça pública agitada. Pleno ventre da metrópole.

A tarde vai morrendo, dolorosamente...

E eu... eu esmoreço e me fano

Lentamente, à feição de menina amorosa...

Homens passam, no entanto, a todo pano,

Homens que nada veem, positivos, e a rosa

Pudenda e nua da emoção e não amam...

Beleza triste dos crepúsculos em prosa,

Inutilmente, sobre o bruhahá urbano.

(QUINTANA, 2012, p. 123) 
O alerta do poeta direcionado à "meninazinha" se estende aos habitantes da cidade que necessitam "alimentar" os olhos e as percepções com a crítica a estética. A paisagem como alimento para os olhos, ou seja, para a percepção, deve ser preservada em seu aspecto e não totalmente diluído pela transformação e metropolização das cidades:

Passeio suburbano

Encontrei uma menina

que me perguntou se era verdade que iam demolir

[aquele belíssimo pé de figueira.

Não, ela não disse belíssimo...

Foi por uma questão de ritmo que acrescentei aqui [esse adjetivo inútil.

Feliz de quem vive ainda no mundo dos substantivos:

o resto é literatura...

Sorri-lhe cumplicemente

(e tristemente)

porque me lembro que em meio ao quintal lá de casa

havia uma paineira enorme

(ultrapassava em altura o primeiro andar de meu [quarto)

Quando florescia, era uma glória!

Talvez fosse ela que impediu que meus sonhos de [menino solitário

tenham sido todos em preto-e-branco.

Uma glória... Até que um dia

foi posta abaixo

simplesmente

porque prejudicava o desenvolvimento das árvores [frutíferas.

Ora, as árvores frutíferas!

Bem sabes, meninazinha, que os nossos olhos também [precisam de alimento (QUINTANA,1986, s/p).

A obra de Quintana está repleta de signos espaciais e poéticas acerca da cidade, Porto Alegre-RS e a sua rua, a rua dos Andradas, antiga rua da Praia (localização do Hotel Magestic, lugar em que ele viveu até sua morte em 1994) é uma das principais referências do poeta na cidade. A consideração da experiência concreta de estar em casa em relação ao espaço, ou ainda, considerar o espaço como um sujeito em sua poesia são marcas da poesia de Mário Quintana.

\section{CONSIDERAÇÕES FINAIS}

Henri Lefebvre debate a apropriação da cidade pela mercadoria, em que as ruas são abarcadas pelo consumo. A colonização da imagem da cidade pela 
publicidade, informação que está subordinada ao consumo, principalmente nos países subdesenvolvidos. A rua é palco em que a população pobre ganha o sustento para a sobrevivência diária, pois não há segurança do dia de amanhã.

A superação da cidade capitalista e o resgate do frescor das ruas se darão pela transformação dos sujeitos mais autônomos, criativos e politicamente engajados. A cidade idealizada por Lefebvre comportaria a obsolescência do espaço, isto quer dizer que estaria em constante mudança, concebida como obra, subordinada apenas aos desejos de todos os habitantes da cidade. A modelagem do espaço urbano seria realizada coletivamente, pelo movimento, pelo encontro, como o "teatro espontâneo" de valorização da liberdade (LEFEBVRE, 2006, p. 133). O espaço urbano da utopia, segundo Lefebvre, seria o gerido pelos próprios anseios dos sujeitos e apropriado pela coletividade.

A modernidade é apreendida pelos poetas em suas andanças, como se pode analisar tanto na poesia de Baudelaire e Mario Quintana. Eles evidenciam que o espaço da cidade é material riquíssimo para se compreender as transformações da modernidade. Essas transformações são tanto espacialmente, como na mentalidade dos sujeitos que habitam no espaço urbano. "Os poetas encontram na rua o lixo da sociedade e a partir dele fazem sua crítica heroica" (BENJAMIN, 1975, p. 14). Os poetas são heróis, pois desbravam pela arte os descaminhos do sistema capitalista. É necessário resgatar essa vontade de flanar, de percorrer o espaço sem medo.

As expressões da arte são meios pelos quais os sujeitos evidenciam suas vivências, o que como afirma Merleau-Ponty (2011), demonstra mais que o mundo físico, pois demonstram o mundo dos signos e da imaterialidade. A imaginação vai além da realidade percebida, por isso os espaços imaginados extrapolam a evidência sensorial (TUAN, 2013, p. 26).

\section{REFERÊNCIAS}

BENJAMIN, W. Charles Baudelaire- um lírico no auge do capitalismo. Tradução de José Carlos Martins Barbosa e Hemerson Alves Baptista. São Paulo: Brasiliense, 1989 (Obras escolhidas, v. 3).

Rua de mão única. Tradução de Rubens Rodrigues Torres Filho e José Carlos Martins Barbosa. São Paulo: Brasiliense, 1987. (Obras escolhidas, v. 2)

A modernidade e os modernos. Tradução de Heindrun Krieger Mendes da Silva, Arlete de Brito e Tania Jatobá. Rio de Janeiro: Tempo Brasileiro, 1975. (Biblioteca Tempo Universitário, 41) 
BERMAN, M. Tudo que é sólido desmancha no ar - A aventura da modernidade. Tradução de Carlos Felipe Moisés, Ana Maria L. Ioriatti e Marcelo Macca. São Paulo: Editora Schwarcz Ltda., 1986.

CARVALHAL, T. F. Mário Quintana dos 8 aos 80. Porto Alegre: Relatório da Diretoria da Samrig, 1985.

DARDEL, E. O homem e a terra: natureza da realidade geográfica. Tradução: Werther Holzer. São Paulo: Perspectiva, 2015 [1954].

EAGLETON, T. Marxismo e crítica literária. Tradução de Matheus Corrêa. São Paulo: Editora Unesp, 2011.

KUSTER, E.; PECHMAN, R. O chamado da cidade: ensaios sobre a urbanidade. Belo Horizonte: Editora UFMG, 2014.

LEFEBVRE, H. O direito à cidade. 4. ed. São Paulo: Centauro, 2006.

. A revolução urbana. Belo Horizonte: Editora UFMG, 1999.

MERLEAU-PONTY, M. Fenomenologia da percepção. 4. ed. São Paulo: Editora WMF Martins Fontes, 2011.

MORIN, E. A cabeça bem feita: repensar a reforma, reformar o pensamento. Tradução de Eloá Jacobina. Rio de Janeiro: Bertran Brasil, 2003.

QUINTANA, M. A cor do invisível. Rio de Janeiro: Objetiva, 2012.

. Baú de espantos. Porto Alegre: Editora do Globo, 1986.

TUAN, Yi, FU. Espaço e lugar: a perspectiva da experiência. Tradução de Lívia de Oliveira. Londrina: Eduel, 2013. 